\section{Chatting fractals and New Math}

\section{Thomas Banchoff}

Mathematical People: Profiles and Interviews. Edited by Donald J. Albers and G.L. Alexanderson. Birkhäuser: 1985. Pp.372.\$24.95.

GeORge Pólya died recently at the age of 97. Here was a legendary teacher whose book How to Solve It and famous film Let Us Teach Guessing inspired generations of students and teachers of mathematics. Would it not have been instructive to have had the opportunity to ask him questions about his career? In recent years, Benoit Mandlebrot's filigreed fractal patterns have burst out of the pages of journal after journal, intriguing scientist and designer alike. How would it be to interview him and get some insight into the process of creating a new kind of mathematics?

In Mathematical People we can enjoy conversations with these figures and two dozen more. This collection of interviews and profiles comes primarily from a very successful series of articles over the past six years in The College Mathematics Jour. nal (formerly The Two-Year College Mathematics Journal). The project began auspiciously with an interview with Polya on the occasion of his ninetieth birthday celebration at Stanford and continued to include some of the most interesting mathematical people of our day.

Here are stories about Persi Diaconis, who left school at 14 to travel with a professional magician, Martin Gardner who explains the origin of his hugely popular Scientific American column, and the immensely prolific, champion collaborator Paul Erdös. We can follow the controversial views of Morris Kline about the New Math, and compare them with the counter-suggestions of Peter Hilton and Paul Halmos. We can contrast the impressions of Richard Courant given by his co-author Herbert Robbins and by the biographer Constance Reid. And we can keep track of dozens of comments about the sometimes opposing relationships between pure and applied mathematics.

What we do not find are answers to the question: "What good is mathematics anyway?". The interviewers are for the most part mathematicians themselves and everyone takes for granted the fact that the creation and communication of mathematics is a worthwhile occupation. Moreover the primary readership for the original articles was teachers of mathematics, so questions tend to centre on different aspects of teaching as opposed to research.

There is wide variation in the depth and the nature of the interviews and profiles, and occasionally a general reader will be left behind when the discussion takes a technical turn. There are also a few other places where one looks in vain for a follow-up to a remark in an interview. For example. what was the subject of Donald Knuth's first published article, in $M A D$ Magazine? Could Albert Tucker please explain why his mentor Solomon Lefschetz had artificial hands? And if David Blackman was not conscious of discrimination all through his schooling, why was it that he only applied to black institutions when he sought his first job?

By and large, however, the interview format is quite successful. By contrast the set pieces taken from popular scientific journals, on Shiing-Shen Chern and Ron

\section{In physical context}

\section{Ivor Grattan-Guinness}

Mathematics and the Search for Knowledge. By Morris Kline. Oxford University Press:1985. Pp.257. \$19.95, £21.

Over several decades, Morris Kline has built up an enviable reputation as the author of a series of popular books on mathematics which include a substantial element of historical material. The first book, Mathematics in Western Culture (Oxford University Press, 1953), remains perhaps the best: the last one, Mathematics: The Loss of Certainty (Oxford University Press, 1980), was probably the worst, with numerous infelicities and errors over the foundations of mathematics and its history. This latest volume lies somewhere between the two.

Here, Kline has returned to applied mathematics, in order to explain how mathematics helps us to understand the physical world. After a "Historical Overview" dealing with various philosophers' positions on the possible existence of an external world, and a discussion of the fallibility of sense perception, he proceeds to a chronological account of episodes in the history of astronomy and mechanics: the Greeks, Copernicus and Kepler, Descartes and Newton. Then electromagnetism is introduced, chiefly as background to relativity and quantum mechanics. The final trio of chapters contains discussions of aspects of the philosophical questions which underpin the book as a whole.

The level of success achieved by Kline in answering these questions may be appraised at first by looking at his use of history. The treatment is more detailed than in his Mathematics and the Physical World (Crowell, 1959), but not much; in particular, there is not actually a great deal of mathematics in the book, the chapters on general relativity and quantum mechanics including hardly any at all. Further, the range of applications is curiously incomplete: there is little or nothing on optics, heat diffusion (the paragraph on p. 202 about Fourier mis-
Graham for example, may be better organized and generally more informative but they lack the spontaneity of the transcribed interviews. The detailed and technical autobiographical reminiscence of Olga Taussky-Todd, originally written as part of a Caltech oral history project, seems out of place in this volume.

Still, one must expect such vagaries in a collection such as this. Many people will find illumination and entertainment in the book, and will be happy to learn that a second volume is in preparation.

Thomas Banchoff is Professor of Mathematics at Brown University. Providence. Rhode Island 02912, USA

represents his philosophy, overrates his mathematics and underrates his physics), hydrodynamics, elasticity theory or engineering mathematics (friction studies, machines of all kinds, cartography and topography, and so on). Probability and statistics earn the falsehood that "the theory of probability ... entered into mathematics quite by chance in connection with games of chance" (p. 189): the virtual absence of these two topics is an especial pity, since work on them greatly extended the range of application of mathematics and raised important questions about knowledge and ignorance, and the epistemological status of approximative theories.

The result of these omissions is not only

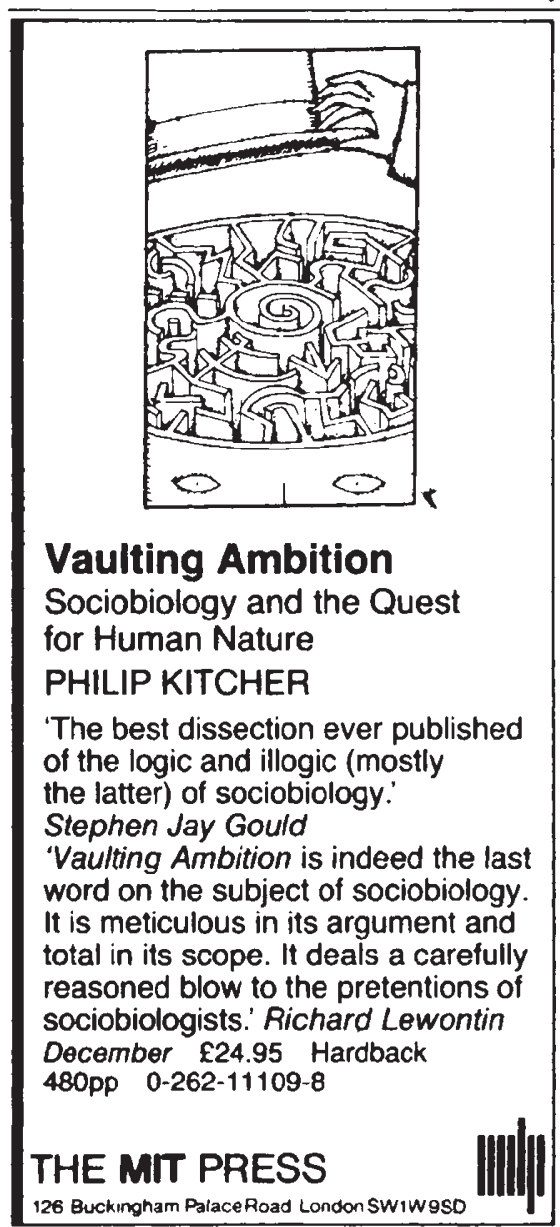


that many essential historical episodes have been passed over, but also that certain crucial aspects of the ways in which mathematics aids our search for knowledge are absent. The terms within which the subject has been tackled are too modest, a failing which also applies to the weight of supporting mathematical apparatus which is brought to bear. There is, for example, no discussion of the calculus, so that the "mathematicization" of continuous media and phenomena cannot be described properly. The clash between different mathematical styles is not

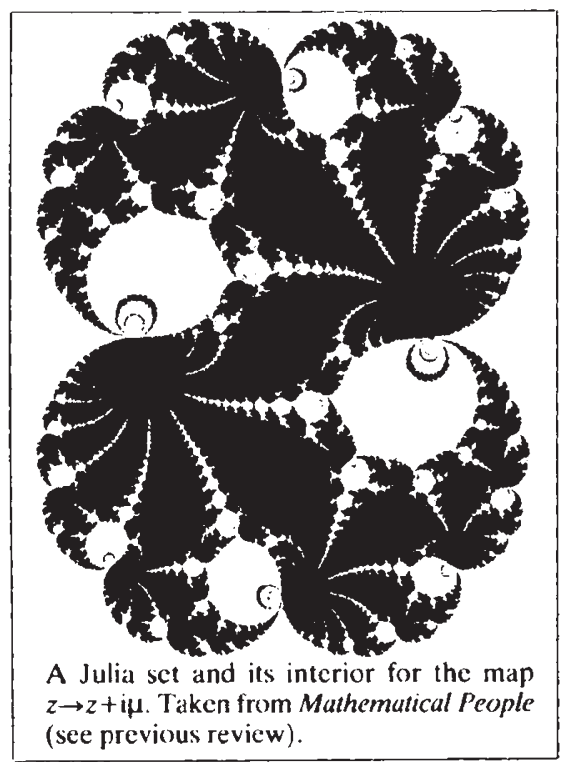

brought out, especially between the geometrical (where the properties of the given configuration play a role) and the algebraic (where formal manipulations of general basic formulae are executed, with deliberate avoidance of geometrical processes); analytical and topological styles bring further differences in their train. Finally, the extent to which a mathematical expression (in any style) reflects the structure of the physical context in which it is used is a matter which should have loomed large, but it does not.

All of these questions involve issues about mathematical proofs, which receive little attention here. But proofs lie at the heart of much of the development of mathematics and thus of its role in the "search for knowledge". The posing of such questions would have served Kline's cause better than the pastiche accounts of philosophers' views on the external world which he does provide (but which have no special bearing on the use of mathematics). This book is best taken as another example of his ability to write breezy and readable surveys of the history of mathematics, and to tackle the philosophical background on the wing; as a contribution to the problem raised. however, Mathematics and the Search for Knowledge is merely a propaedeutic.

Ivor Grattan-Guinness is Reader in Mathematics, Middlesex Polytechnic, Enfield, Middlesex EN3 $4 S F, U K$

\section{Where lies the science?}

\section{Anthony W. Clare}

The Psychoanalytic Movement. By Ernest Gellner. Paladin: 1985. Pp.241. Pbk £3.50. Psychoanalysis and Beyond. By Charles Rycroft. Edited by Peter Fuller. Chatto \& Windus: 1985. Pp.310. Hbk £10.95; pbk 14.95. To be published early next year in the United States by Chicago University Press.

Psychoanalysis: Freud's Cognitive Psychology. By Matthew Hugh Erdelyi. W.H. Freeman: 1985. Pp.303. Hbk \$24.95, $£ 25 ; p b k \$ 14.95, £ 14.95$.

Decline and Fall of the Freudian Empire. By Hans Eysenck. Viking: 1985. Pp.224. £12.95.

TIE way in which the psychoanalytic school was formed raises profound questions concerning its status as a science and suggests that it might, with benefit, be viewed as a secular religion. Certainly, one will look in vain elsewhere in science for another example of a body of theoretical knowledge linked so intrinsically, so inextricably, with the individual who first propounded it. In no other branch can one find an absence of an external arbitrator, that is to say someone outside the control of the system itself and able to pass independent comment on its claims, achievements and shortcomings. In the case of psychoanalysis, the location of the criterion of its truth is, in the words of Ernest Gellner, "determined by the ideas of the system itself; the well of truth is within the ramparts and not outside". The possession of this truth is not handed down in seminars and courses of instruction, though these play a small part, but by way of participation in the training analysis. As the apostolic succession from St Peter is handed down from the bishops to newly ordained priests, so the authentic link with Freud is maintained and continued by means of the transfer of authority from training analyst to analysand.

The religious analogy does not end there. As intellectual and rational criticism of revealed religious dogma is interpreted as a closing of the mind and heart to truth, and in no way a valid comment on the basic validity of the truth itself, so criticism of psychoanalysis is rejected on the grounds that either the critic has never been analysed, in which case he is resisting the need to be analysed (which itself is worthy of interpretation), or he has been analysed and his criticisms reflect an incomplete or prematurely terminated process, the result no doubt of fear over what might be revealed. And the religious analogy becomes uncomfortable when one examines the schisms and factions within the domain of psychoanalysis, with each school claiming to have adhered the closest to the spirit as well as the law laid down by the supreme founder.

The question which Gibbon asked of Christianity is equally applicable to psychoanalysis: by what means did the new vision obtain so remarkable a victory? In a stylish, witty and deceptively readable book, Gellner exposes the secular religious nature of the psychoanalytic enterprise. He admits that a compelling. charismatic belief must possess more than merely the promise of succour in a plague and links with the background convictions of the age. It must engender a tension in the neophyte or potential convert. It must tease and worry him with its promise and its threat. The doctrine to be embraced must contain the promise of a salvation that is earnestly desired. There must be plausible reasons for believing its claims and also good reasons for doubting it or fearing its truth. The middle ground between acceptance and rejection must be denied and the issue of whether it is or is not true must be trans-empirical and untestable. The fact that confidence in psychoanalysis is devoid of any visible means of support hardly seems to diminish its authority: indeed, argues Gellner.

were its means of support visible, they would be subject to evaluation; and the assertion would have given hostages to fortune, and also conceded its own ordinary, human status - mak ing its own contentions arguable, negotiable. imitable, publicly available rather than tied to a single source.

One psychoanalyst who has been particularly conscious of the contentiousness of the psychoanalytical factions is Charles Rycroft who, in so far as he identifies with any particular school, tends to align him. self with the English-speaking school uniting such disparate practitioners as Winnicott, Fairbairn, Balint and Bowlby. This group, as Rycroft pointed out in an essay entitled "Psychoanalysis and Beyond". contained in the collection of his writings under the same title, repudiated any royal road to becoming an analyst even to the extent of encouraging trainees to have part of their teaching under the supervision of a member of another faction. Rycroft underwent, as far as one can tell, an orthodox Freudian analysis and in 1956 presented a paper to the British PsychoAnalytical Society which challenged the prevailing theory of symbolism by suggesting that it is not a regressive or defensive phenomenon but rather "a general capacity of the mind" which could be deployed in manifold different ways. According to Peter Fuller, the editor of the book, the Society received this modification, the first serious one advanced to a theory of some 40 years standing, with reserve while it struggled to protect the orthodox position. It was the first of a number of theoretically awkward questions that Rycroft was to raise, on such issues as dreams, fantasies and the nature of psychoanalysis itself.

In 1968, he wrote A Critical Dictionary 